\title{
US device industry and FDA "colluded" on legislation to weaken regulatory oversight
}

\author{
When we first published this News story (BMJ 2015;351:h6820, \\ doi:10.1136/bmj.h6820), we reported that Diana Zuckerman, \\ president of the National Center for Health Research, told The \\ $B M J$ that no more than two dozen non-profit organizations that \\ are members of the Patient, Consumer, and Public Health \\ Coalition had been invited by the FDA to help develop any \\ provisions of the 21st Century Cures Act or its Senate \\ companion bill.
}

This should have read that Zuckerman told The BMJ that "none of the more than two dozen" non-profit organizations had been invited to help develop provisions of the proposed act. This error was corrected online on 18 December 2015. We apologise for this error.

Cite this as: BMJ 2015;351:h6911

๑ BMJ Publishing Group Ltd 2015 